\title{
A real-time digital bedside card of emergency room: a new concept
}

\author{
Wen-Han Chang ${ }^{1,2,3,4,5}$, Ming-Kun Huang ${ }^{1,2}$, Jui-Ping Lin ${ }^{1,6}$, Ding-Kuo Chien ${ }^{1,2,3,4,5}$ \\ ${ }^{1}$ Department of Emergency Medicine, MacKay Memorial Hospital, Taipei, Taiwan; ${ }^{2}$ Department of Medicine, Mackay Medical College, Taipei, \\ Taiwan; ${ }^{3}$ Mackay Junior College of Medicine, Nursing, and Management, Taipei, Taiwan; ${ }^{4}$ Institute of Mechatronic Engineering, National Taipei \\ University of Technology, Taiwan; ${ }^{5}$ Institute of Injury Prevention and Control, Taipei Medical University, Taipei, Taiwan; ${ }^{6}$ Department of Nursing, \\ MacKay Memorial Hospital, Taipei, Taiwan \\ Correspondence to: Ding-Kuo Chien. Department of Emergency Medicine, MacKay Memorial Hospital, 92, Section 2, Chungshan North Road, \\ Taipei, Taiwan. Email: anderson1021dr@gmail.com.
}

Received: 23 April 2019; Accepted: 22 November 2019; Published: 30 December 2019.

doi: $10.21037 / \mathrm{ht} .2019 .11 .03$

View this article at: http://dx.doi.org/10.21037/ht.2019.11.03

A traditional bedside card (Figure 1) is designed for patient identity and is positioned on the wall above bed board. However, we have noticed that the traditional bedside cards have been left unused in the emergency room (ER) due to the inconvenience of changing new patient information after the former patient was discharged or hospitalized. In addition, the bed card (Figure 1) in emergency departments is a small sticker $\left(8 \times 13 \mathrm{~cm}^{2}\right)$ and is positioned on the bottom of bed. The card, a sticker, contains only basic information (name/medical record number/birthday). However, it is unknown why other information including diagnosis, admission date, and the bed number is usually blank. The ER nurses are possibly too occupied with patient care to fill out the bedside card and the bed card, and the card locations are typically not easy to access.

The workload of the emergency staff is very heavy, and the patients' locations change frequently. After ER physicians visit the patients, some must remain in bed, awaiting laboratory results and anticipating treatments. After the ER physicians' re-evaluation, some patients are discharged with medicine, while others are admitted to the hospital or transferred to other hospitals. Therefore, the information on bedside card must change frequently to correctly reflect the patients' information and status. If the actual information on the bedside card is not updated quickly with the change of each patient, the medical staff may provide the incorrect treatment to the incorrect patient, thereby increasing the risk of medical litigation. Furthermore, the beds in the ER are limited and need to be fully utilized. Therefore, a real-time bedside card recording

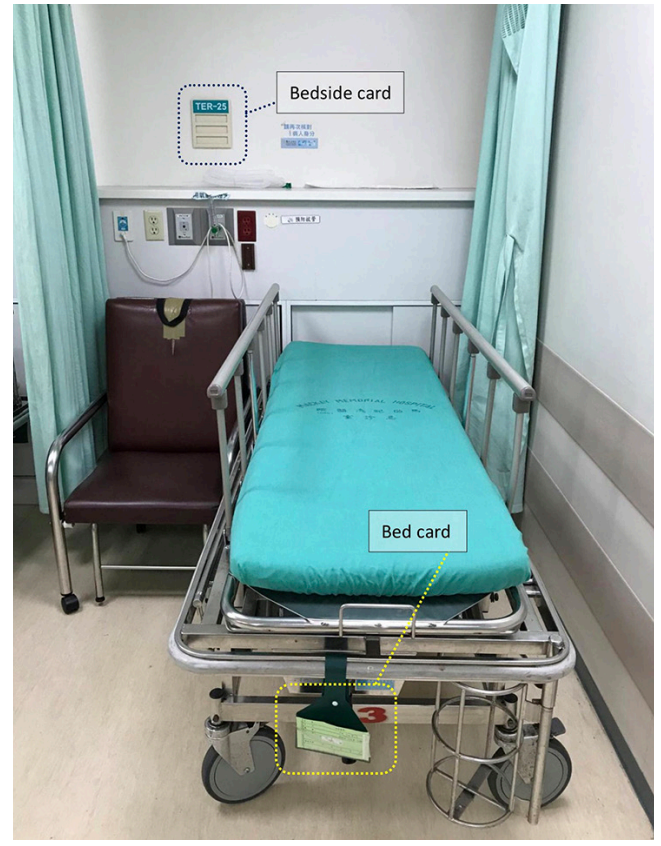

Figure 1 Traditional bedside card (blue dot) and bed card (yellow dot) in the emergency department.

the correct patient information is very important.

Due to the above reasons, we propose a new concept of a real-time, ER digital bedside card (Figure 2), which is synchronized electronically with the hospital information system (HIS). To the best of our knowledge, this concept has not been applied at ERs previously. There are many predictable benefits to this concept. First, after a patient 


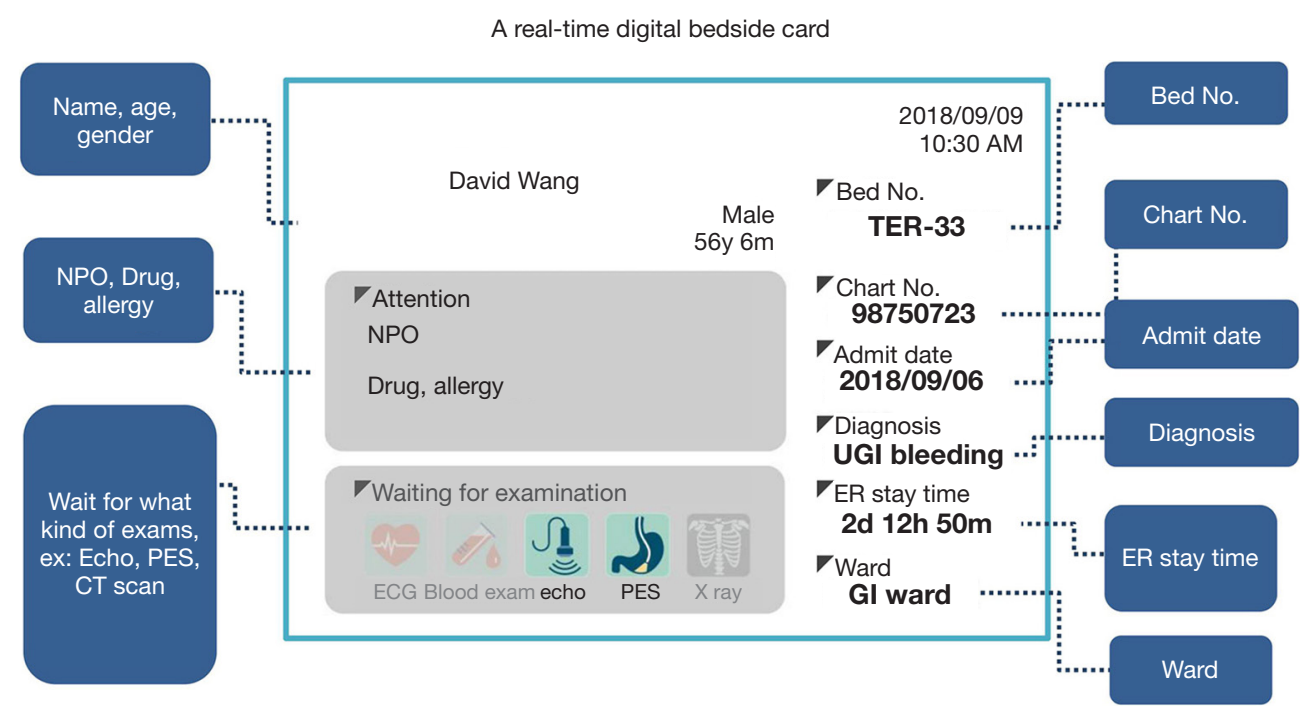

Figure 2 Contents of a real-time digital bedside card.

is assigned to a bed number $\mathrm{X}$ by the HIS, the number $\mathrm{X}$ bedside card will simultaneously display the patient's information for the escorts who transport the patient and double check his/her medical wristband. Second, the patient information on the ER digital bedside card is comprehensive and real-time, such as NPO, the anticipated procedure (such as ultrasound, endoscope, blood exam, CT scan, and $\mathrm{X}$-ray), and the admission status of the patient. Patients and their families can quickly understand the patient's current condition by viewing the bedside card. This will reduce the frequency of questions directed to the ER medical staff and may even increase patient/family satisfaction. Third, a real-time ER digital bedside card will assist the ER staff in identifying the patient at the bedside and will assist in administering the correct treatments to the correct patient. We believe this concept may improve the quality of ER care, increase ER patient safety, decrease ER staff workload, and reduce ER medical disputes.

Currently, we are actively establishing real-time ER digital bedside cards at our hospital and conducting a study to test our predictions. We would greatly appreciate if we could share our results for your consideration in the future.

\section{Acknowledgments}

Funding: None.

\section{Footnote}

Provenance and Peer Review: This article was commissioned by the editorial office, Health Tecbnology. This article did not undergo external peer review.

Conflicts of Interest: All authors have completed the ICMJE uniform disclosure form (available at http://dx.doi. org/10.21037/ht.2019.11.03). WHC serves as an Editorin-Chief of Health Technology. The other authors have no conflicts of interest to declare.

Ethical Statement: The authors are accountable for all aspects of the work in ensuring that questions related to the accuracy or integrity of any part of the work are appropriately investigated and resolved.

Open Access Statement: This is an Open Access article distributed in accordance with the Creative Commons Attribution-NonCommercial-NoDerivs 4.0 International License (CC BY-NC-ND 4.0), which permits the noncommercial replication and distribution of the article with the strict proviso that no changes or edits are made and the original work is properly cited (including links to both the formal publication through the relevant DOI and the license). See: https://creativecommons.org/licenses/by-nc$\mathrm{nd} / 4.0 /$.

doi: $10.21037 /$ ht.2019.11.03

Cite this article as: Chang WH, Huang MK, Lin JP, Chien

DK. A real-time digital bedside card of emergency room: a new concept. Health Technol 2019;3:11. 